\title{
Nitrogen Analogues of Polycyclic Aromatic Hydrocarbons
}

\section{Category}

Synthesis of

Materials and

Unnatural Products

\section{Key words}

polycyclic aromatic hydrocarbons

azaaromatics

azides

Synt<smiles>O=Cc1c2ccccc2c(C=O)c2ccccc12</smiles><smiles>CCOC(=O)CN</smiles>

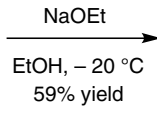<smiles>CCOC(=O)/C(N)=C/c1c2ccccc2c(/C=C(\N)C(=O)OCC)c2ccccc12</smiles><smiles></smiles><smiles></smiles><smiles>CCOC(=O)c1cc2c3cccc4nc(C(=O)OCC)cc(c5cccc(n1)c35)c42</smiles>

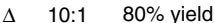

hv $\quad 1: 1$ $90 \%$ yield
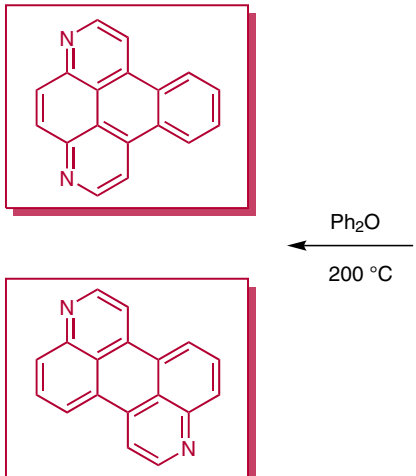

$200^{\circ} \mathrm{C}$

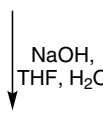

Significance: Nitrogen-containing polyaromatic hydrocarbons are well-known for their stability and spectacular optoelectronic properties. The authors report a facile and efficient approach to access structurally demanding polycyclic azaarenes: diazabenzopyrene and diazaperylene. In general, synthetic approaches to azaarenes are limited to aromatic amines as starting materials. The visible-light photocyclization of vinyl azide derivatives is an important alternative to overcome the above-mentioned limitation.
Comment: The authors demonstrate the efficient synthesis of nitrogen-containing polyaromatic hydrocarbons starting from vinyl azide functionalized anthracene substrates. The photocatalyst-free, visible-light photocyclization of vinyl azide derivatives of anthracenes suggests possible applications for the syntheses of previously inaccessible nitrogen-containing polycyclic aromatics. 